\section{Research Square}

\title{
Viable Medical Waste Chain Network Design by Considering Risk and Robustness
}

Reza Lotfi ( $\sim$ reza.lotfi.ieng@gmail.com )

Yazd University https://orcid.org/0000-0001-5868-8467

\section{Bahareh Kargar}

Iran University of Science and Technology

\section{Alireza Gharehbaghi}

Sharif University of Technology

\section{Gerhard-Wilhelm Weber}

Poznan University of Technology: Politechnika Poznanska

\section{Research Article}

Keywords: Viable, Medical waste, Network design, Resiliency, Sustainable, Robust optimization

Posted Date: August 17th, 2021

DOl: https://doi.org/10.21203/rs.3.rs-765430/v1

License: () (i) This work is licensed under a Creative Commons Attribution 4.0 International License. Read Full License

Version of Record: A version of this preprint was published at Environmental Science and Pollution Research on October 21 st, 2021. See the published version at https://doi.org/10.1007/s11356-02116727-9. 
Viable medical waste chain network design by considering

risk and robustness

Reza Lotfi ${ }^{\text {a*}}$, Bahareh Kargar ${ }^{\text {b }}$, Alireza Gharehbaghi ${ }^{c}$, Gerhard-Wilhelm Weber ${ }^{\text {d }}$

a Department of Industrial Engineering, Yazd University, Yazd, Iran and Behineh Gostar Sanaye Arman, Tehran, Iran;

${ }^{\mathrm{b}}$ School of Industrial Engineering, Iran University of Science and Technology, Tehran, Iran;

${ }^{c}$ Department of Industrial engineering, Sharif University of Technology, Iran;

${ }^{\mathrm{d}}$ Poznan University of Technology, Faculty of Engineering Management, Poznan, Poland, and IAM, METU, Ankara, Turkey.

\section{Abstract}

Medical Waste Management (MWM) is an important and necessary problem in the COVID-19 situation for treatment staff. When the number of infectious patients grows up and amount of MWMs increases day by day. We present Medical Waste Chain Network Design (MWMCND) that contains Health Center (HC), Waste Segregation (WS), Waste Purchase Contractor (WPC) and landfill. We propose to locate WS to decrease waste and recover them and send them to the WPC. Recovering medical waste like metal and plastic can help the environment and return to the production cycle. Therefore, we proposed a novel Viable MWCND by a novel two-stage robust stochastic programming that considers resiliency (flexibility and network complexity) and sustainable (energy and environment) requirements. Therefore, we try to consider risks by Conditional Value at Risk (CVaR) and improve robustness and agility to demand fluctuation and network. We utilize and solve it by GAMS CPLEX solver. The results show that by increasing the conservative coefficient, the confidence level of $\mathrm{CVaR}$ and waste recovery coefficient increases cost function and population risk. Moreover, increasing demand and scale of the problem make to increase the cost function.

Keywords: Viable; Medical waste; Network design; Resiliency; Sustainable; Robust optimization.

\footnotetext{
*reza.lotfi.ieng@gmail.com;
} 


\section{Introduction}

32 Medical Waste Management (MWM) is a critical problem in the COVID-19 situation. In the

33 COVID-19 condition, amount of infectious patients grow up and amount of MWMs increase. As

34 a result, we must pay more attention to MWMs and improve waste disposal. Many workers that

35 do waste disposal, this subject threatens them very much. MWMs include infectious waste,

36 hazardous waste, radioactive waste and general waste (municipal solid waste). The WHO classifies

37 medical waste into sharps, infectious, pathological, radioactive, pharmaceuticals, other (including

38 toilet waste produced at hospitals). About $85 \%$ of MWMs are general waste and $15 \%$ of MWMs

39 are infectious waste, hazardous waste, radioactive waste (Tsai, 2021). Therefore, the importance

40 of MWMs, make many researchers contribute this subject and present mathematical approach and

41 decision support system. Some researchers consider a location-routing problem for medical waste

42 management (Suksee \& Sindhuchao, 2021; Tirkolaee, Abbasian, \& Weber, 2021). Others

43 investigate reverse logistics by the mathematical model (Sepúlveda, Banguera, Fuertes, Carrasco,

44 \& Vargas, 2017; Suksee \& Sindhuchao, 2021). Also, some scientists analysis of MWM systems

45 by multi-criteria-decision approach (Aung, Luan, \& Xu, 2019; Narayanamoorthy et al., 2020). The

46 objective of these tools is to improve waste management performance and decrease risks for

47 workers that we can see in Figure 1.

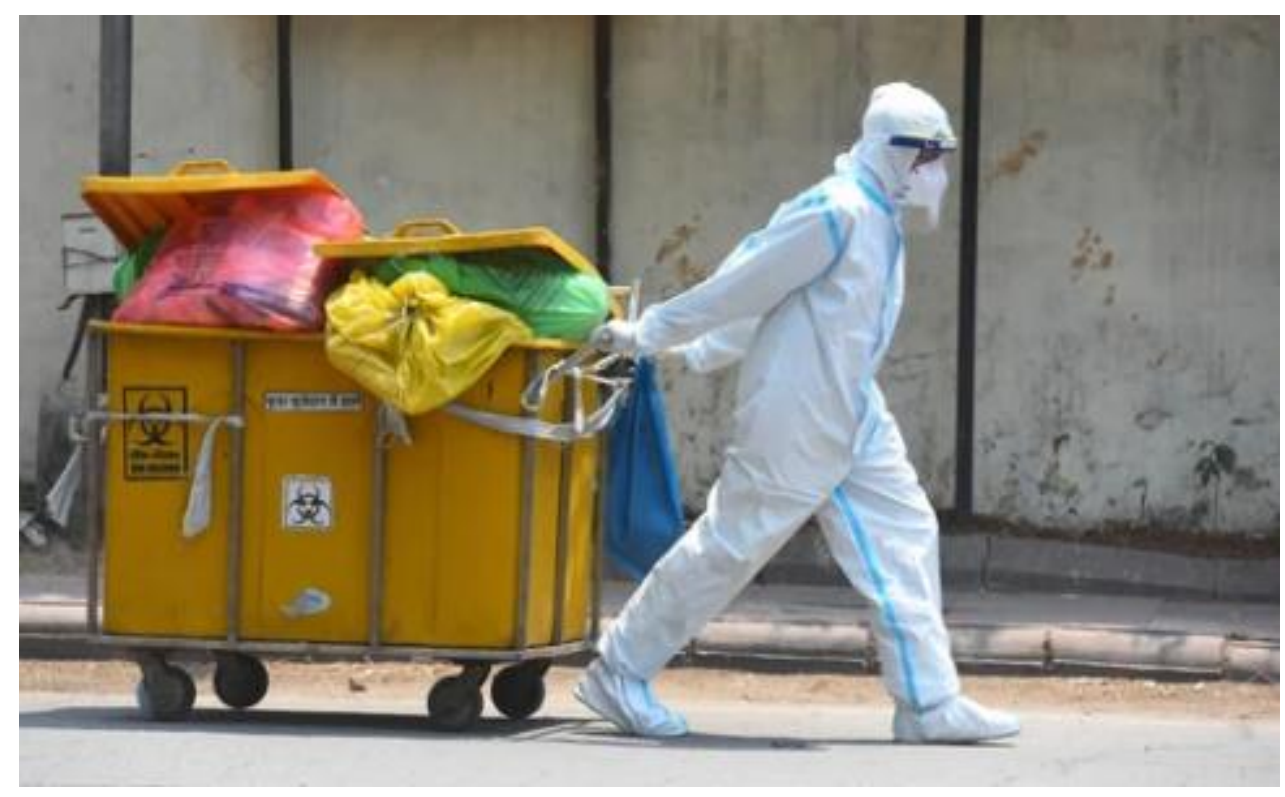

Figure 1. MWM in the COVID-19 situation. 
One of the new discussions in the present age is the viability of network design in post-pandemic adaptation. The viability of networks that are proposed by Ivanov and Dolgui (2020) is integrated agility, resilience and sustainability in the network. Therefore, it is needed to suggest a systematic and mathematical model for setting up Viable Medical Waste Chain Network Design (VMWCND). Because improving the performance of waste management is urban need and make to prevent COVID-19 outbreak. Eventually, we should design a new mathematical model to consider agility, resilience, sustainability, risks and robustness to cope with environmental requirements and disruption.

Eventually, the innovation of this research and the main objective is as follows:

- First time designing viable medical waste chain network design (VMWCND),

- Considering robustness and risk in VMWCND.

The paper is organized as follows. In Section 2, we survey on related work in scope of MWCND. In Section 3, the VMWCND and risk-averase VMWCND is stated. In Section 4, the results of research and sensitivity analysis are presented. In Section 5, the managerial insights and practical implications is discussed. In Section 6, the conclusion is summarized.

\section{Survey on recent MWCND}

64 The amount of waste has increased because of the COVID-19 situation. Therefore, researchers 65 research to manage, improve and decrease losses from medical centers. We survey on the recent investigation on MWCND is as follows.

67 Mantzaras and Voudrias (2017) considered an optimization model for medical waste in Greece. They tried to minimize total cost include location and transfer between location. The Genetic Algorithm (GA) is applied to solve the model. Budak and Ustundag (2017) designed a reverse logistic for multiperiod, multitype waste products. The model's objective was to minimize total cost and the model's decision included location, flow, inventory. The case was in Turkey. They found that by increasing waste amounts, the numbers of facilities and strategies are changed. Wang, Huang, and He (2019) designed a two-stage reverse logistics network for urban healthcare waste with multi-objective and multi-period. In stage one, they predicted the amount of medical waste, and in the second stage, they minimized total cost and environmental impact. 
Kargar, Paydar, and Safaei (2020) presented a reverse supply chain for medical waste. They used mix-integer programming (MIP) to model problem. The objectives included total costs, technology selection and the total medical waste stored that are minimized. A robust possibilistic programming (RPP) approach are applied to cope with uncertainty. A Fuzzy Goal Programming (FGP) method is embedded to solve the objectives. The real case study is investigated in Babol, Iran. Other works of Kargar, Pourmehdi, and Paydar (2020) studied a reverse logistics network design for MWM in the COVID-19 situation. They minimized the total costs, transportation and treatment MW risks, and maximized the amount of uncollected waste. They employed the Revised

Multi-Choice Goal Programming (RMGP) method. Homayouni and Pishvaee (2020) surveyed hazardous hospital waste collection and disposal network design problem with a bi-objective robust optimization (RO) model. The objectives include total costs, the total operational and transportation risk. An augmented $\varepsilon$-constraint (AUGEPS) method is embedded to solve the problem. The real case study is investigated in Tehran, Iran.

Yu, Sun, Solvang, and Zhao (2020) considered a reverse logistics network design for MWM in epidemic outbreaks in Wuhan (China). The objectives included risk at health centers, risk related to the transportation of medical waste and total cost. They solved the model by Fuzzy Programming (FP) approach for multi-objective. They determine temporary transit centers and temporary treatment centers in their model. In addition, Yu, Sun, Solvang, Laporte, and Lee (2020) studied a stochastic network design problem for hazardous WM. They minimized cost and transportation cost of hazardous waste and the population exposure risk. They applied stochastic programming with Sample average approximation (SAA) for scenario reduction. They solved the model by Goal Programming (GP). Z Saeidi-Mobarakeh, R Tavakkoli-Moghaddam, M Navabakhsh, and H Amoozad-Khalili (2020) presented bi-level programming (BP) for a hazardous WM problem. They used an enviormental approach for upper-level and routing and cost for lowerlevel. They solve Mix-Integer Non-Linear Programming (MINLP) by GA.

In addition, Zahra Saeidi-Mobarakeh, Reza Tavakkoli-Moghaddam, Mehrzad Navabakhsh, and Hossein Amoozad-Khalili (2020) developed a robust bi-level optimization model to model hazardous WCND. They suggested a robust optimization approach to cope with the uncertainty. Also, the decisions of the model include location, determining capacity and routing. Eventually, a commercial solver is utilized to solve the model. Tirkolaee et al. (2021) surveyed a sustainable 
106 fuzzy multi-trip location-routing problem for MWM during the covid-19 outbreak. They 107 embedded Fuzzy Chance-Constrained Programming (FCCP) technique to tackle the uncertainty. 108 Therefore, they implemented Weighted GP (WGP) method to analyze and solve the problem. A 109 case study is determined in Sari, Iran to show the performance of the proposed model. Tirkolaee 110 and Aydin (2021) suggested a sustainable MWM for collection and transportation for pandemics. 111 They minimized total cost and the total risk exposure imposed by the collection. Eventually, a 112 commercial solver is utilized to solve the model with Meta-Goal Programming (MGP) for multi113 objective. Shadkam (2021) designed a reverse logistics network for COVID-19 and vaccine waste 114 management. They utilized Cuckoo Optimization Algorithm (COA). They tried to minimize total 115 cost. Nikzamir, Baradaran, and Panahi (2021) suggested a location routing network design for 116 MWM that tried to minimize the total cost and risks of population contact with infectious waste. 117 They offered a Mix-Integer Linear Programming (MILP) and solved it by a hybrid meta-heuristic 118 algorithm based on Imperialist Competitive Algorithm (ICA) and GA. Li et al. (2021) surveyed a 119 Vehicle Routing Problem (VRP) for MWM by considering transportation risk. They suggested MILP for 120 time window VRP and developed a Particle Swarm Optimisation (PSO) algorithm to solve large-scale 121 problems.

Table 1. Survey of MWCND.

\begin{tabular}{|c|c|c|c|c|c|c|c|c|c|c|}
\hline \multirow[b]{2}{*}{ Reference } & \multirow[b]{2}{*}{ Kind } & \multirow[b]{2}{*}{ Decsion } & \multicolumn{5}{|c|}{ Objectives } & \multirow[b]{2}{*}{ Methodology } & \multirow[b]{2}{*}{ 芯 } & \multirow[b]{2}{*}{$\begin{array}{l}\text { Case } \\
\text { study }\end{array}$} \\
\hline & & & 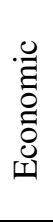 & 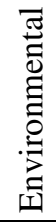 & 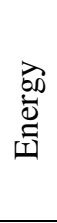 & 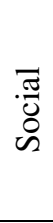 & 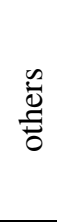 & & & \\
\hline $\begin{array}{l}\text { (Mantzaras } \\
\text { \& Voudrias, } \\
\text { 2017) }\end{array}$ & - & $\begin{array}{l}\text { Location, } \\
\text { capacity }\end{array}$ & $\checkmark$ & - & - & - & - & MILP+ GA & - & Greece \\
\hline $\begin{array}{l}\text { (Budak \& } \\
\text { Ustundag, } \\
\text { 2017) }\end{array}$ & - & $\begin{array}{l}\text { Location, } \\
\text { flow, } \\
\text { inventory }\end{array}$ & $\checkmark$ & - & - & - & - & MILP & - & Turkey \\
\hline $\begin{array}{l}\text { (Wang et al., } \\
\text { 2019) }\end{array}$ & Green & $\begin{array}{l}\text { Location, } \\
\text { flow, } \\
\text { inventory }\end{array}$ & $\checkmark$ & $\checkmark$ & - & - & - & MILP & - & $\begin{array}{c}\text { Shanghai, } \\
\text { China }\end{array}$ \\
\hline $\begin{array}{l}\text { (Kargar, } \\
\text { Paydar, et } \\
\text { al., 2020) }\end{array}$ & - & $\begin{array}{l}\text { Location, } \\
\text { flow, } \\
\text { inventory }\end{array}$ & $\checkmark$ & - & - & - & $\checkmark$ & MILP+ FGP & RPP & $\begin{array}{c}\text { Babol, } \\
\text { Iran }\end{array}$ \\
\hline $\begin{array}{l}\text { (Kargar, } \\
\text { Pourmehdi, } \\
\text { et al., 2020) }\end{array}$ & - & $\begin{array}{l}\text { Location, } \\
\text { flow }\end{array}$ & $\checkmark$ & - & - & - & $\checkmark$ & MILP+RMGP & - & Iran \\
\hline $\begin{array}{l}\text { (Homayouni } \\
\text { \& Pishvaee, } \\
2020 \text { ) }\end{array}$ & - & $\begin{array}{l}\text { Location, } \\
\text { flow }\end{array}$ & $\checkmark$ & - & - & - & $\checkmark$ & $\begin{array}{c}\text { MILP+ } \\
\text { AUGEPS }\end{array}$ & RO & $\begin{array}{l}\text { Tehran, } \\
\text { Iran }\end{array}$ \\
\hline
\end{tabular}




\begin{tabular}{|c|c|c|c|c|c|c|c|c|c|c|}
\hline $\begin{array}{l}\text { (Yu, Sun, } \\
\text { Solvang, \& } \\
\text { Zhao, 2020) }\end{array}$ & - & $\begin{array}{l}\text { Location, } \\
\text { flow }\end{array}$ & $\checkmark$ & - & - & - & $\checkmark$ & MILP+FP & - & $\begin{array}{l}\text { Wuhan, } \\
\text { China }\end{array}$ \\
\hline $\begin{array}{l}\text { (Yu, Sun, } \\
\text { Solvang, } \\
\text { Laporte, et } \\
\text { al., 2020) }\end{array}$ & - & $\begin{array}{l}\text { Location, } \\
\text { flow }\end{array}$ & $\checkmark$ & - & - & - & $\checkmark$ & MILP+GP & Stocastic & $\begin{array}{c}\text { Numerical } \\
\text { example } \\
\text { (NE) }\end{array}$ \\
\hline $\begin{array}{l}\text { (Z Saeidi- } \\
\text { Mobarakeh } \\
\text { et al., 2020) }\end{array}$ & - & $\begin{array}{c}\text { Routing, } \\
\text { environmenta } \\
1\end{array}$ & $\checkmark$ & $\checkmark$ & - & - & - & $\begin{array}{c}\text { MINLP } \\
(\mathrm{BP})+\mathrm{GA}\end{array}$ & - & $\begin{array}{l}\text { Isfahan, } \\
\text { Iran }\end{array}$ \\
\hline $\begin{array}{l}\text { (Zahra } \\
\text { Saeidi- } \\
\text { Mobarakeh } \\
\text { et al., 2020) }\end{array}$ & - & $\begin{array}{l}\text { Location, } \\
\text { capacity, } \\
\text { routing }\end{array}$ & $\checkmark$ & - & - & - & $\checkmark$ & $\operatorname{MILP}(\mathrm{BP})$ & $\mathrm{RO}$ & $\begin{array}{l}\text { Isfahan, } \\
\text { Iran }\end{array}$ \\
\hline $\begin{array}{l}\text { (Tirkolaee } \\
\text { et al., 2021) }\end{array}$ & Sustainable & $\begin{array}{l}\text { Location, } \\
\text { routing }\end{array}$ & $\checkmark$ & - & - & - & - & MILP+WGP & FCCP & Sari, Iran \\
\hline (Tirkolaee & & & & & & & & & & \\
\hline $\begin{array}{l}\text { \& Aydin, } \\
\text { 2021) }\end{array}$ & Sustainable & $\begin{array}{l}\text { Location, } \\
\text { routing }\end{array}$ & $\checkmark$ & - & - & - & $\checkmark$ & MILP+ MGP & - & $\mathrm{NE}$ \\
\hline $\begin{array}{l}\text { (Shadkam, } \\
\text { 2021) }\end{array}$ & - & $\begin{array}{l}\text { Location, } \\
\text { flow }\end{array}$ & $\checkmark$ & - & - & - & - & $\mathrm{MILP}+\mathrm{COA}$ & - & $\mathrm{NE}$ \\
\hline $\begin{array}{l}\text { (Nikzamir } \\
\text { et al., 2021) }\end{array}$ & Green & $\begin{array}{l}\text { Location, } \\
\text { routing }\end{array}$ & $\checkmark$ & - & - & - & $\checkmark$ & $\begin{array}{c}\text { MILP+ICA } \\
\text { GA }\end{array}$ & - & $\mathrm{NE}$ \\
\hline $\begin{array}{l}\text { (Li et al., } \\
\text { 2021) }\end{array}$ & - & Routing & $\checkmark$ & - & - & - & - & MILP + PSO & - & $\mathrm{NE}$ \\
\hline $\begin{array}{l}\text { This } \\
\text { research }\end{array}$ & $\begin{array}{c}\text { Viable } \\
\text { (Resilience } \\
\text { +sutainable } \\
\text { +agile) }\end{array}$ & $\begin{array}{l}\text { Location, } \\
\text { flow }\end{array}$ & $\checkmark$ & - & $\begin{array}{lll}- & - \\
-1\end{array}$ & - & - & MILP & $\begin{array}{c}\text { RO } \\
\text { Stochastic }\end{array}$ & Tehran \\
\hline
\end{tabular}

122 The classification of the literature is addressed in Table 1. It can be seen; researchers do not survey 123 the VMWCND problem. This study investigates the VMWCND problem and used mathematical 124 problems to locate the best place for MWCND.

125 The main innovation of this research is as follows:

- First time designing VMWCND,

- Considering agility, resilience, sustainability, robustness and risk-averse.

\section{3. Problem description}

129 In this research, we try to design VMWCND. The previous section shows a lack of research in 130 resilience, sustainability and agility MWCND. In the present study, we have Health Center (HC),

131 Waste Segregation (WS), Waste Purchase Contractor (WPC), landfill that waste move through 132 this network. Eventually, we present VMWCND through resilience strategy (flexible and scenario133 based capacity and node complexity), sustainability constraints (energy and environmental 
134 pollution), and agility (balance flow and demand satisfaction). We need to locate WS to improve 135 and recover waste and consider sustainability and environmental requirements in this situation. Assumptions:

- All wastes should be transferred to HC (agility),

- All forward MWCND constraints include flow and capacity constraint is active,

- Sustainability constraints include allowed emission and energy consumption are added (sustainability),

143 - Using scenario-based robust optimization against risks (robustness, risk, resiliency)

144 (Ivanov, 2020; Lotfi, Mehrjerdi, Pishvaee, Sadeghieh, \& Weber, 2021).

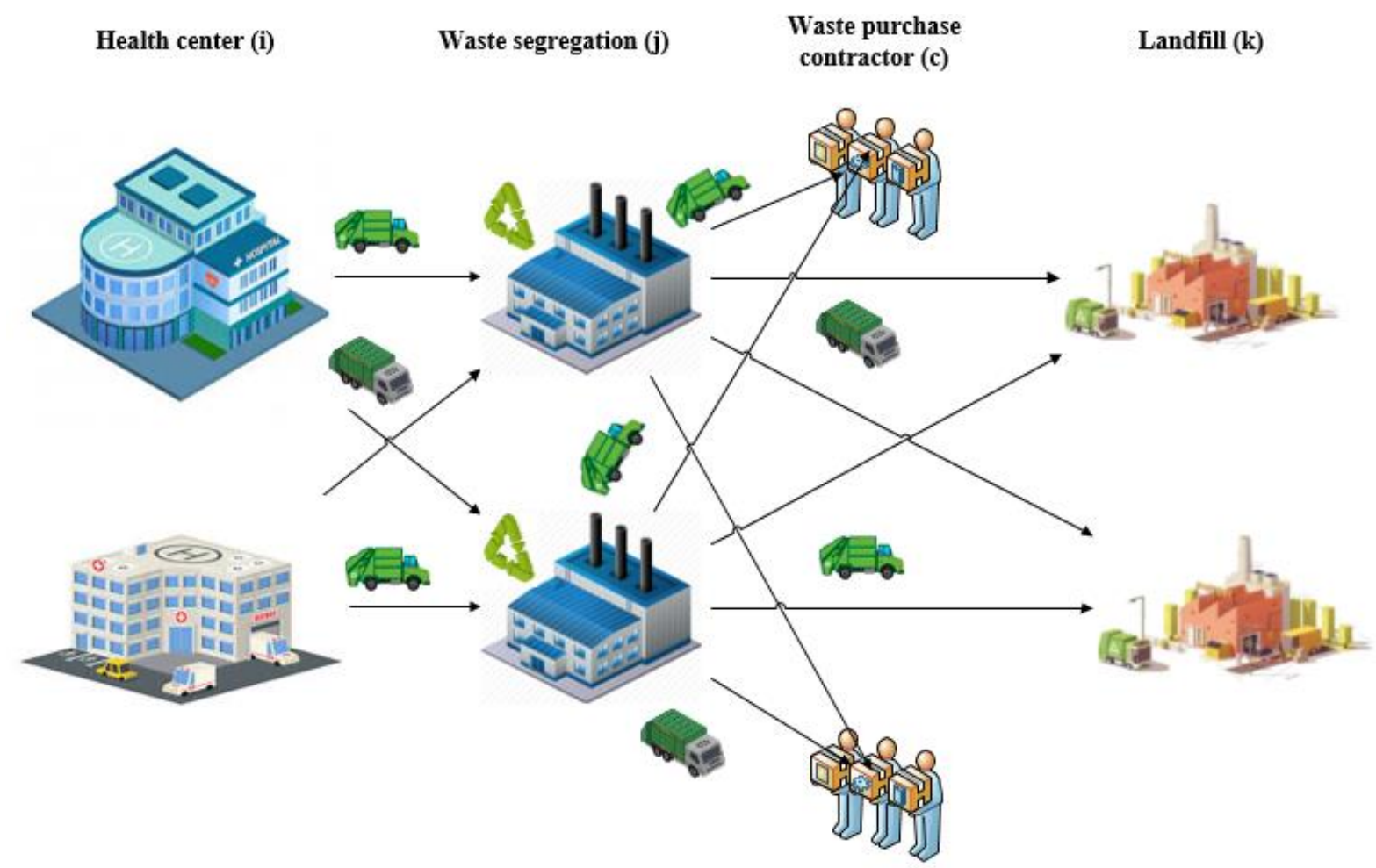

Figure 2. Viable medical waste chain network design (VMWCND).

145 Notations:

146 Indices: 
$i \quad$ Index of Health Center (HC) $i$,

$j \quad$ Index of Waste Segregation (WS) $j$,

$c \quad$ Index of Waste Purchase Contractor (WPC) $c$,

$k \quad$ Index of landfill $k$,

$t \quad$ Index of time period,

$s \quad$ Index of scenario;

147 Parameters:

$w w_{i t s} \quad$ Waste generated in $\mathrm{HC} i$ for time period $t$ under scenario $s$,

$v i j_{i j t s} \quad$ Variable cost from $\mathrm{HC} i$ to WS $j$ for time period $t$ under scenario $s$,

$v j c_{j c t s} \quad$ Variable cost from WS $j$ to WPC $c$ for time period $t$ under scenario $s$,

$v j k_{j k t s} \quad$ Variable cost from WS $j$ to the landfill $k$ for time period $t$ under scenario $s$,

$f j_{j} \quad$ Cost of activation WS $j$,

$E m i j_{i j t s} \quad$ Emission $\mathrm{CO}_{2}$ for transfering from $\mathrm{HC} i$ to WS $j$ for time period $t$ under scenario $s$,

$E m j c_{j c t s}$ Emission $\mathrm{CO}_{2}$ for transfering from WS $j$ to WPC $c$ for time period $t$ under scenario $s$,

$E m j k_{j k s}$ Emission $\mathrm{CO}_{2}$ for transfering from WS $j$ to landfill $k$ for time period $t$ under scenario $s$,

Enij $_{i j t s}$ Energy consumption for transfering from $\mathrm{HC} i$ to WS $j$ for time period $t$ under scenario $s$, 
$E_{\text {Enjc }}$ Ents $\quad$ Energy consumption for transfering from WS $j$ to WPC $c$ for time period $t$ under scenario $s$,

$E n j k_{j k t s}$ Energy consumption for transfering from WS $j$ to landfill $k$ for time period $t$ under scenario $s$,

$\operatorname{Capj}_{j t s} \quad$ Capacity WS $j$ for time period $t$ under scenario $s$,

$p_{s} \quad$ Probably of scenario $s$,

$\lambda \quad$ Coefficient of conservative,

$E M S C_{t s}$ Maximum allowed emission for time period $t$ under scenario $s$,

$E N S C_{t s}$ Maximum allowed energy consumption for time period $t$ under scenario $s$,

$\rho_{j} \quad$ Coefficient of availability of WS $j$,

Mbig Big positive number,

eps Very little positive number,

$\alpha \quad$ The confidence level for conditional value at risk,

$\pi \quad$ Waste recovery coefficient,

Threshold of node complexity for resiliency,

$\varphi \quad$ The ratio of $\mathrm{HC}$ to WS.

popij $_{i j t s}$ Population risk contact from HC $i$ to WS $j$ for time period $t$ under scenario $s$, popjc $_{\text {jcts }}$ Population risk contact from WS $j$ to WPC $c$ for time period $t$ under scenario $s$, popjk $_{j k t s}$ Population risk contact from WS $j$ to landfill $k$ for time period $t$ under scenario $s$;

Binary variables: 
$x_{j} \quad$ If WS $j$ is established, equal 1; otherwise 0 ;

Continues Variables:

$w i j_{i j t s} \quad$ Waste transshipment from HC $i$ to WS $j$ for time period $t$ under scenario $s$,

$w j k_{j k t s} \quad$ Waste transshipment from WS $j$ to landfill $k$ for time period $t$ under scenario $s$,

$w j c_{j c t s} \quad$ Waste transshipment from WS $j$ to WPC $c$ for time period $t$ under scenario $s$;

151 Auxiliary Variables:

FC Fix cost of establishing WS

$V C_{s} \quad$ Variable cost for scenario $s$,

$\Gamma_{s} \quad$ Fix cost and variable cost for scenario $s$.

VaR Value at Risk

$\Delta \quad$ Auxiliary variable for linearization max function,

$y i j_{i j t s} \quad$ Auxiliary and binary variable for linearization sign function for $w i j_{i j t s}$,

$y j k_{j k t s} \quad$ Auxiliary and binary variable for linearization sign function for $w j k_{j k t s}$,

$y j c_{j c t s} \quad$ Auxiliary and binary variable for linearization sign function for $w j c_{j c t s}$.

\section{3.1. VMWCND mathematical model}

$\operatorname{minimize} Z=(1-\lambda) \sum_{s} p_{s} \Gamma_{s}+\lambda\left(\frac{\max \left(\Gamma_{s}\right)+C V a R_{(1-\alpha)}\left(\Gamma_{s}\right)}{2}\right)$

subject to:

$$
\begin{aligned}
& \Gamma_{s}=F C+V C_{s}, \\
& F C=\sum_{j} f j_{j} x_{j},
\end{aligned}
$$




$$
V C_{s}=\sum_{t}\left(\sum_{i} \sum_{j} v i j_{i j t s} w i j_{i j t s}+\sum_{j} \sum_{k} v j k_{j k t s} w j k_{j k t s}+\sum_{j} \sum_{c} v j c_{j c t s} w j c_{j c t s}\right), \quad \forall s
$$

Agility constraints (flow constraints):

$$
\begin{array}{lc}
\sum_{j} w i j_{i j t s}=w w_{i t s}, & \forall i, t, s \\
\sum_{j} w i j_{i j t s} \leq \sum_{j} w j k_{j k t s}+\sum_{j} w j c_{j c t s}, & \forall i, k, c, t, s \\
\sum_{i} w i j_{i j t s}=\sum_{k} w j k_{j k t s}+\sum_{c} w j c_{j c t s}, & \forall j, t, s \\
\sum_{k} w j k_{j k t s} \geq(1-\pi) \sum_{i} w i j_{i j t s}, & \forall j, t, s
\end{array}
$$

Resiliency constraints (flexible and scenario-based capacity and node complexity)

$$
\begin{array}{ll}
\sum_{k} w j k_{j k t s}+\sum_{c} w j c_{j c t s} \leq \rho_{j} \operatorname{Capj}_{j t s} x_{j}, & \forall j, t, s \\
\frac{\sum_{j} x_{j}}{|i|} \geq \varphi, & \\
\sum_{i} w i j_{i j t s}+\sum_{k} w j k_{j k t s}+\sum_{c} w j c_{j c t s} \leq T T, & \forall j, t, s
\end{array}
$$

Sustainability constraints (allowed emission and energy consumption):

$$
\begin{gathered}
\sum_{i} \sum_{j} E m i j_{i j t s} w i j_{i j t s}+\sum_{j} \sum_{k} E m j k_{j k t s} w j k_{j k t s} \\
+\sum_{j} \sum_{c} E m j c_{j c t s} w j c_{j c t s} \leq E M S C_{t s}, \\
\sum_{i} \sum_{j} E n i j_{i j t s} w i j_{i j t s}+\sum_{j} \sum_{k} E n j k_{j k t s} w j k_{j k t s} \\
+\sum_{j} \sum_{c} E n j c_{j c t s} w j c_{j c t s} \leq E N S C_{t s},
\end{gathered}
$$




$$
\begin{aligned}
& \text { Pop }_{s}=\sum_{t}\left(\sum_{i} \sum_{j} \text { popij }_{i j t s}\left[w i j_{i j t s}\right]+\sum_{j} \sum_{k} \text { popjk }_{j k t s}\left[w j k_{j k t s}\right]\right. \\
&\left.+\sum_{j} \sum_{c} \text { popjc }_{j c t s}\left[w j c_{j c t s}\right]\right) \\
& \sum_{s} p_{s} \text { Pop }_{s} \leq \theta
\end{aligned}
$$

Decision variables:

$$
\begin{array}{lc}
x_{j} \in\{0,1\}, & \forall j \\
w i j_{i j t s}, w j k_{j k t s}, w j c_{j c t s} \geq 0 . & \forall i, j, c, \\
& k, t, s
\end{array}
$$

153 The objective (1) considered minimizing the weighted expected value, minimax and conditional

154 value at risk of the cost function and for all scenarios. This form of the cost function is proposed 155 for robustness and risk-averse against disruption with worst condition. Constraints (2) include fix 156 and variable costs. Constraints (3) show fix-costs that include fix-cost activating WS for all 157 periods. Constraints (4) indicate the variable costs of HC, WS, WPC and landfill. Constraints (5) 158 show waste transshipment from HC to WS. Constraints (6) to (7) are flow constraints in forwarding 159 VMWCND. Constraints (8) determine the ratio of waste that goes to the landfill. Constraints (9) 160 are flexible capacity constraints for WS that less than the capacity of WS system. Constraints (10) 161 are resilience constraints and the number of WS is greater than the coefficient of HC. Constraints 162 (11) are resilience constraints and show node complexity in WS that summation of input and output 163 of every WS is less than the threshold. Constraints (12) guarantee the network's total environmental 164 emissions are less than allowed emission. Constraints (13) guarantee that the network's total energy 165 consumption is less than the allowed energy consumption. Constraints (14) risks related to the 166 transportation of medical waste. Constraints (15) show summation risks related to medical waste 167 transport that contact with population is less than threshold. Constraints (16) to (17) are decision 168 variables, and constraints (16) are facilities location for WC and binary variables and constraints 169 (17) are flow variables that are positive between facilities.

\subsection{Linearization of VMWCND}


171 The objective function (1) is nonlinear and makes the model mixed-integer nonlinear programming 172 (MINLP). We trnsform them to mixed-integer programming (MIP) by mathematical method to 173 improve time solution and solve smoothly (Gondal \& Sahir, 2013; Sherali \& Adams, 2013).

174 Linearizing max and sign function:

175 Suppose: If $\beta=\max \left(\Omega_{s}\right)$, then we can change $\beta \geq \Omega_{s}, \forall s$.

176 Suppose: If $\beta_{s}=\operatorname{sign}\left(\Omega_{s}\right)$, then we can change $\beta_{s} \leq 1+\frac{\Omega_{s}}{\text { Mbig }}-e p s, \beta_{s} \geq \frac{\Omega_{s}}{\text { Mbig }}, \forall s$.

177 We used Conditional Value at Risk (CVaR), which is a coherent risk measure. Uryasev and Rockfeller 178 designed the CVaR criterion applied to a novel embed risk measure (Soleimani \& Govindan, 2014). CVaR 179 (also known as the expected shortfall) is considered as a measure for assessing the risk. CVaR is embedded 180 in portfolio optimization to better risk management (Goli, Zare, Tavakkoli-Moghaddam, \& Sadeghieh, 181 2019; Kara, Özmen, \& Weber, 2019). This measure is the average of losses are beyond the VaR point in 182 confidence level. CVaR has a higher consistency, coherence, and conservation than other risk-related 183 criteria.

184 We used linearization for model (1) by operational research method. Solving the model by MIP is 185 more straightforward than MINLP in the solver in equations (18) to (30), and this methods decrease 186 time solution and the complexity of the model.

\section{Linearization of VMWCND}

$\operatorname{minimize} Z=(1-\lambda) \sum_{s} p_{s} \Gamma_{s}+0.5\left(\lambda \Delta+C \operatorname{VaR} R_{(1-\alpha)}\left(\Gamma_{s}\right)\right)$,

subject to:

$$
\begin{array}{lc}
\Delta \geq \Gamma_{s} & \forall s \\
C V a R_{(1-\alpha)}\left(\Gamma_{s}\right)=V a R+\frac{1}{1-\alpha} \sum_{s} p_{s} v_{s}, & \forall s \\
v_{s} \geq \Gamma_{s}-V a R, & \forall s \\
v_{s} \geq 0, & \forall s
\end{array}
$$




$$
\begin{array}{rlr}
\text { Pop }_{s}= & \sum_{t}\left(\sum_{i} \sum_{j} p o p i j_{i j t s} y i_{j j t s}+\sum_{j} \sum_{k} p o p j k_{j k t s} y j k_{j k t s}\right. & \\
& \left.+\sum_{j} \sum_{c} p o p j c_{j c t s} y j c_{j c t s}\right), & \\
y i j_{j i t s} \leq 1+\frac{w i j_{i j t s}}{M b i g}-e p s, & \forall i, j, t, s \\
y i j_{i j t s} \geq \frac{w i j_{i j t s}}{M b i g}, & \forall i, j, t, s \\
y j k_{j k t s} \leq 1+\frac{w j k_{j k t s}}{M b i g}-e p s, & \forall j, k, t, s \\
y j k_{j k t s} \geq \frac{w j k_{j k t s}}{M b i g}, & \forall j, k, t, s \\
y j c_{j c t s} \leq 1+\frac{w j c_{j c t s}}{M b i g}-e p s, & \forall j, c, t, s \\
y j c_{j c t s} \geq \frac{w j c_{j c t s}}{M b i g}, & \forall j, c, t, s \\
y i j_{i j t s}, y j k_{j k t s}, y j c_{j c t s} \in\{0,1\}, & \forall i, j, c,
\end{array}
$$

Constraints (2)-(13), (15)-(17).

188 The complexity of linearization of VMWCND includes numbers of binary, positive, free variables 189 and constraints is indicated in equations (31) to (34). As can be seen, one of the essential factors

190 for constraints, positive and free variables, is scenario sets. Relation between scenario and 191 constraints, positive and free variables is completely linear.

$$
\begin{aligned}
& \text { Binary variables }=|j|+|t| \cdot|s|(|i| \cdot|j|+|j| \cdot|c|+|j| \cdot|k|), \\
& \text { Positive variables }=|t| \cdot|s|(|i| \cdot|j|+|j| \cdot|c|+|j| \cdot|k|)+1, \\
& \text { Free variables }=6+2|s|, \\
& \text { Constraints }=6+4|s|+|t| \cdot|s|(|i|+|i| \cdot|k| \cdot|c|+4|j|+2+|i| \cdot|j|+|j| \cdot|c|+|j| \cdot|k|) .
\end{aligned}
$$

192 We suggested scenario reduction and new algorithms to remove constraints and binary variables. 193 This subject can help solve minimum time. 


\section{Results and discussion}

195 We surveyed hospitals in Tehran, Iran, and estimated parameters from data of MWCND by 196 managers of health centers. The performance of the mathematical model is presented. The number 197 of indices are defined in Table 2 and the values of the parameters are determined in Table 3 . The 198 probability of occurrence is the same and optimistic, pessimistic and possible scenarios has 199 happened.

Table 2. Number of indices, constraints, and variables for case study.

\begin{tabular}{|c|c|c|c|c|c|c|c|}
\hline Problem & $|i| \cdot|j| .|c| .|k| \cdot|t| \cdot|s|$ & 党 & 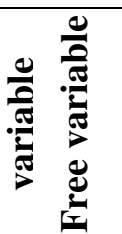 & 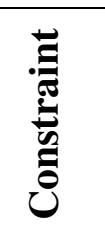 & $\begin{array}{c}\text { Cost } \\
\text { function }\end{array}$ & $\begin{array}{c}\text { Time } \\
\text { solution }\end{array}$ & $\begin{array}{c}\text { Population } \\
\text { risk }\end{array}$ \\
\hline P1-main & 118.4 .3 .1 .3 .3 & $4396 \quad 4393$ & 12 & 8818 & 1520407 & 9.422 & 54026.33 \\
\hline
\end{tabular}

Table 3. Parameters of case study.

\begin{tabular}{|c|c|c|c|c|c|}
\hline Parameters & Value & Unit & Parameters & Value & Unit \\
\hline$w w_{i t s}$ & $\begin{array}{l}\mathrm{U}(1000,1100)(0.8 \\
+0.4(s-1) /(|s|-1))\end{array}$ & Ton & $\lambda$ & 50 & $\%$ \\
\hline$v i i_{i j t s}$ & $\mathrm{U}(0.5,1)$ & \$/Ton & $E M S C_{t s}$ & $\begin{array}{l}\mathrm{U}(20000,40000)(|i| \\
|j|+|j||c|+|j||k|)\end{array}$ & Ton \\
\hline$v j c_{j c t s}$ & $\mathrm{U}(0.5,1)$ & \$/Ton & $E N S C_{t s}$ & $\begin{array}{l}\mathrm{U}(40000,50000)(|i| \\
|j|+|j||c|+|j||k|)\end{array}$ & MJ \\
\hline$v j k_{j k t s}$ & $\mathrm{U}(0.5,1)$ & $\$ /$ Ton & $\rho_{j}$ & 90 & $\%$ \\
\hline$f j_{j}$ & $\mathrm{U}(500000,600000)$ & $\$$ & $\alpha$ & 5 & $\%$ \\
\hline$E m i j_{i j t s}$ & $\mathrm{U}(2,4) / 1000$ & Ton & $\pi$ & 90 & $\%$ \\
\hline$E^{2 m j} c_{j c t s}$ & $\mathrm{U}(2,4) / 1000$ & Ton & $T T$ & $\begin{array}{c}3000(|i||j|+|j||c|+ \\
|j||k|)\end{array}$ & Ton \\
\hline$E m j k_{j k t s}$ & $\mathrm{U}(2,4) / 1000$ & Ton & $\varphi$ & 1 & $\%$ \\
\hline$E_{n i j}{ }_{i j t s}$ & $\mathrm{U}(4,5) / 1000$ & MJ & $\theta$ & $\begin{array}{c}200(|i||j|+|j||c|+|j| \\
|k|) /|s|\end{array}$ & Person \\
\hline$E n j c_{j c t s}$ & $\mathrm{U}(4,5) / 1000$ & MJ & popij $_{i j t s}$ & {$[\mathrm{U}(100,200)]$} & Person \\
\hline$E n j k_{j k t s}$ & $\mathrm{U}(4,5) / 1000$ & MJ & popjc $_{j c t s}$ & {$[\mathrm{U}(150,200)]$} & Person \\
\hline
\end{tabular}




\begin{tabular}{cccccc} 
Capj $_{j t s}$ & $\begin{array}{c}\mathrm{U}(222222,233333 \\
(0.8+0.4(s-1) /(\end{array}$ & Ton & popjk $_{j k t s}$ & {$[\mathrm{U}(100,200)]$} & Person \\
& $|s|-1))$ & & & \\
$p_{s}$ & $100 /|s|$ & $\%$ & & []: Sign function & \\
\hline
\end{tabular}

202 We applied a computer with this configuration: CPU 3.2 GHz, Processor Core i3-3210, 6.00 GB 203 RAM, 64-bit operating system. Finally, we solve the mathematical models by GAMS-CPLEX 204 solver.

Table 4. Assigning location for the VMWCND facility.

\begin{tabular}{cccccc}
\hline Problem: P1 & $\begin{array}{c}\text { Binary } \\
\text { variable }\end{array}$ & $\begin{array}{c}\text { Robat } \\
\text { karim }\end{array}$ & Shurabad & Parand & $\begin{array}{c}\text { Nasim } \\
\text { shahr }\end{array}$ \\
\hline WPC & $x j_{j}$ & 1 & 0 & 1 & 0 \\
\hline
\end{tabular}

206 We show the potential location for assigning HC, WS, WPC, landfill in Tehran, Iran (cf. Figure 207 3). After solving the model, it suggests that we activate WS and determine the location and the 208 flow of VMWCND components. The objective function is 1520407 in Table 2 and the final 209 location-allocation is drawn in Figure 4. Finally, we calculate population risk (left-hand side of 210 Constraint (15)) that are 54026.33 persons. Eventually, we compare VMWCND with risk and 211 worst case and without risk and worst case in Table 5. We can see that by embedding risk and 212 worst case, the cost function is almost $1.65 \%$ greater than without risk and worst case.

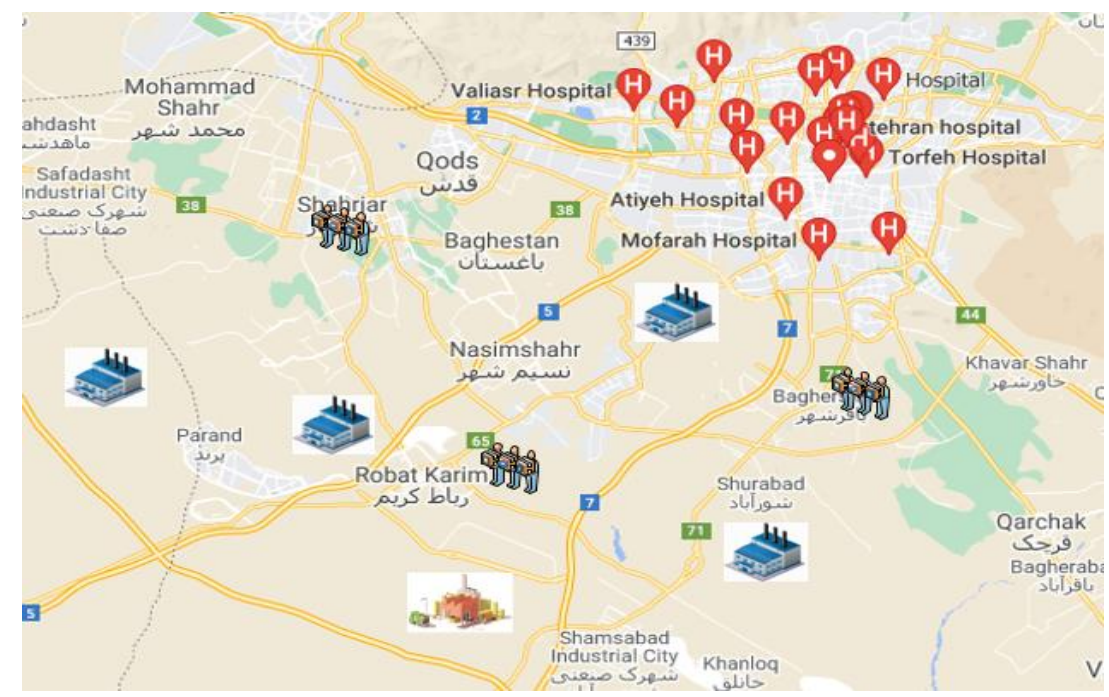

Figure 3. Potential location for the facilities. 
Table 5. Comparing P1- VMWCND with risk and worst case and without risk and worst case.

\begin{tabular}{cccc}
\hline Model & P1- VMWCND & $\begin{array}{c}\text { P1- VMWCND } \\
\text { without risk and } \\
\text { worst case }\end{array}$ & Gap \\
\hline P1-main & 1520407 & 1495346.97 & $1.65 \%$ \\
\hline
\end{tabular}

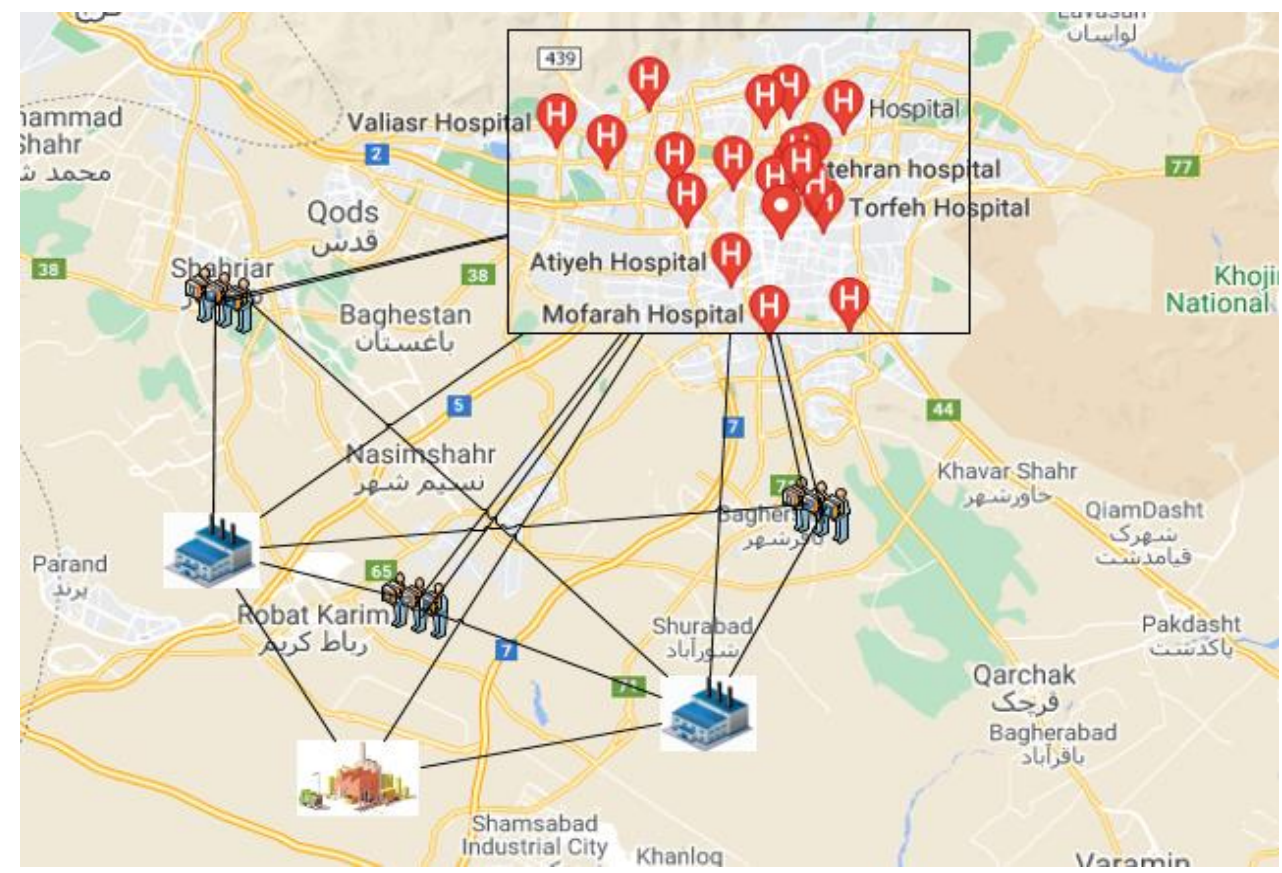

Figure 4. Final location for VMWCND facility.

\section{4.1. Variation on the conservative coefficient}

217 The conservative coefficient $(\lambda)$ is the amount of conservative decision-makers. We change it by 218 varying between $0-1$ that the conservation of decision-maker has been changed.

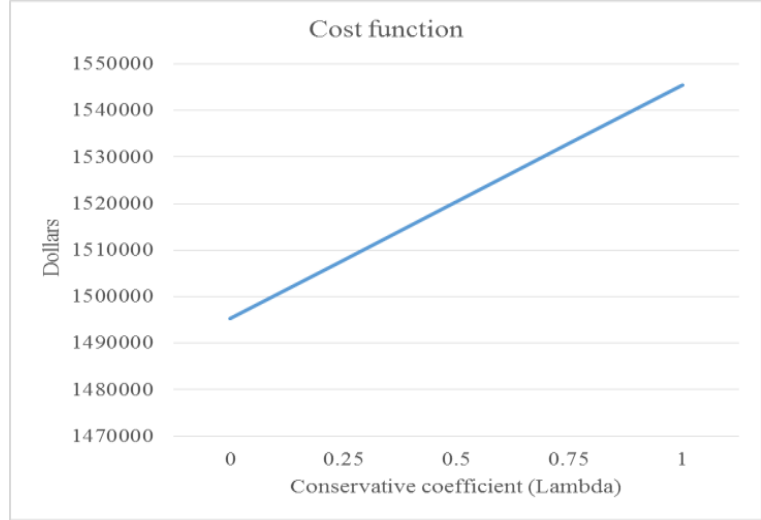

Figure 5. Cost function for different Lambda.

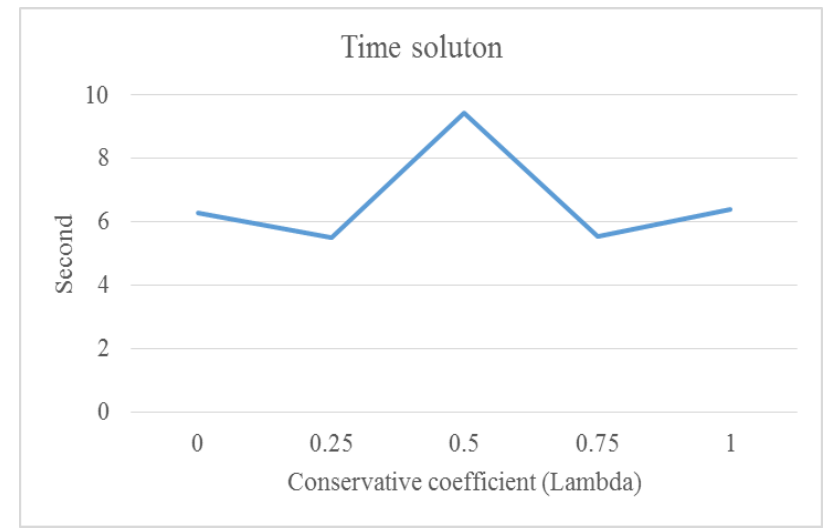

Figure 6. Time solution for different Lambda. 
219 If the conservative coefficient increases to 1, the cost function grows in Table 6, Figure 5 and Figure 6. If 220 the conservative coefficient increases $50 \%$, the cost function will increase by $1.65 \%$, but time solution and 221 population risk do not change significantly.

Table 6. Effects of variation of conservative coefficient.

\begin{tabular}{cccccc}
\hline Problem & $\begin{array}{c}\text { Conservative } \\
\text { coefficient }(\lambda)\end{array}$ & $\begin{array}{c}\text { Cost } \\
\text { function }\end{array}$ & $\begin{array}{c}\text { Time } \\
\text { solution }\end{array}$ & $\begin{array}{c}\text { Cost } \\
\text { variation }\end{array}$ & $\begin{array}{c}\text { Population } \\
\text { risk }\end{array}$ \\
\hline P1 & 0.00 & 1495346.97 & 6.289 & $-1.65 \%$ & 54026.33 \\
P1 & 0.25 & 1507877.11 & 5.52 & $-0.82 \%$ & 54026.33 \\
P1-main model & 0.5 & 1520407.25 & 9.422 & $0.00 \%$ & 54026.33 \\
P1 & 0.75 & 1532937.39 & 5.526 & $0.82 \%$ & 54026.33 \\
P1 & 1.00 & 1545467.53 & 6.4 & $1.65 \%$ & 54026.33 \\
\hline
\end{tabular}

\section{4.2. Variation on confidence level of CVaR}

224 The confidence level of $\operatorname{CVaR}(\alpha)$ is the amount of risk-averse decision-makers. If the confidence 225 level grows up, we can see, the cost function will increase (cf. Table 7 and Figure 7). By increasing $2262 \%$ for confidence level, the cost function increase $0.03 \%$.

Table 7. Effects of the confidence level of CVaR.

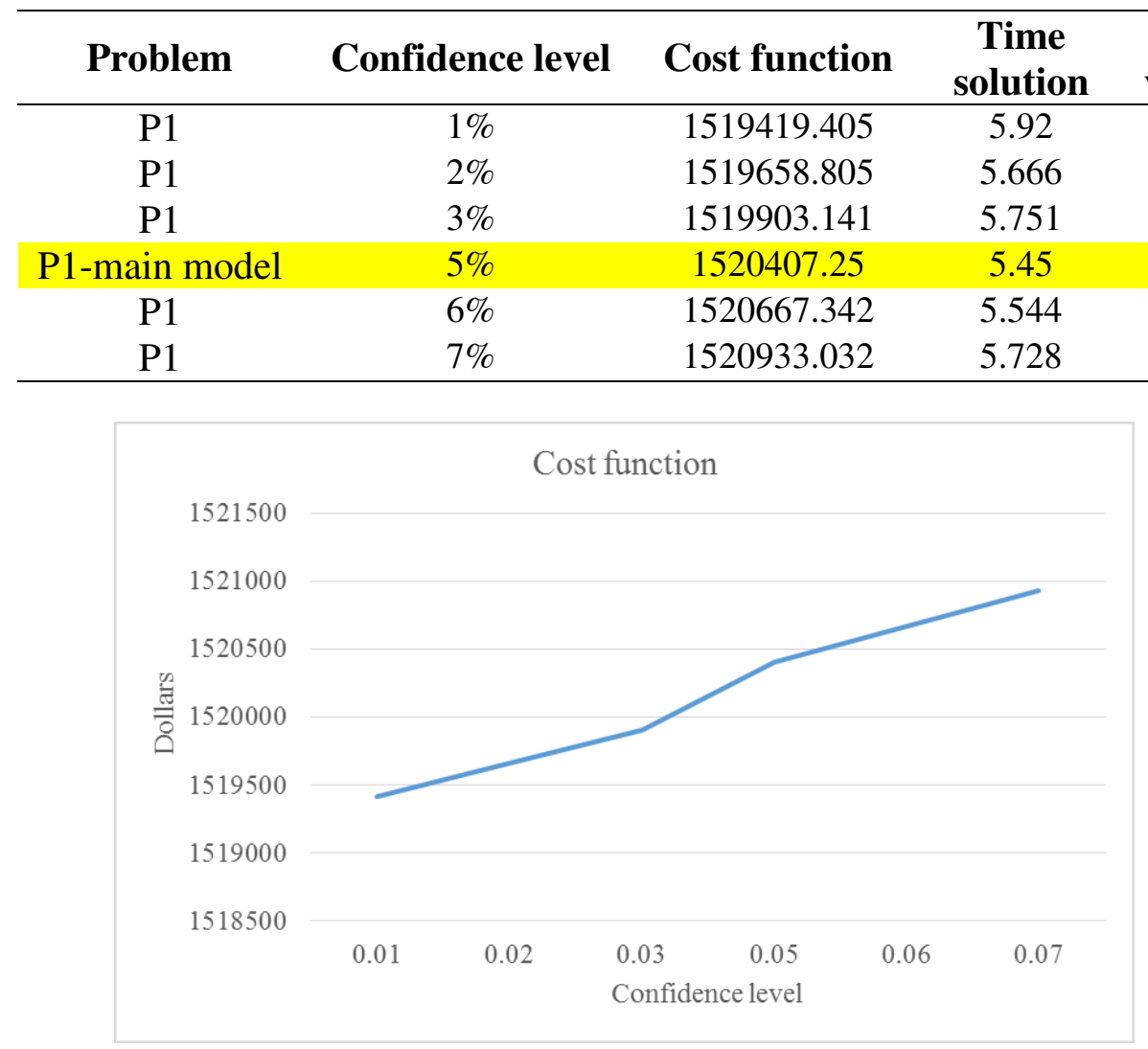

Figure 7. Effects of the confidence level of CVaR. 


\section{4.3. Variation on waste recovery coefficient}

229 The waste recovery coefficient $(\pi)$ is the ratio of waste that goes to landfills. If the waste recovery 230 coefficient grows, we can see that the cost function and population risk will decrease (cf. Figure

231 8, Figure 9 and Table 8). Increasing waste recovery coefficient, transportation to WPC increases 232 and then the cost function increase. But this issue helps systems to use and recover waste.

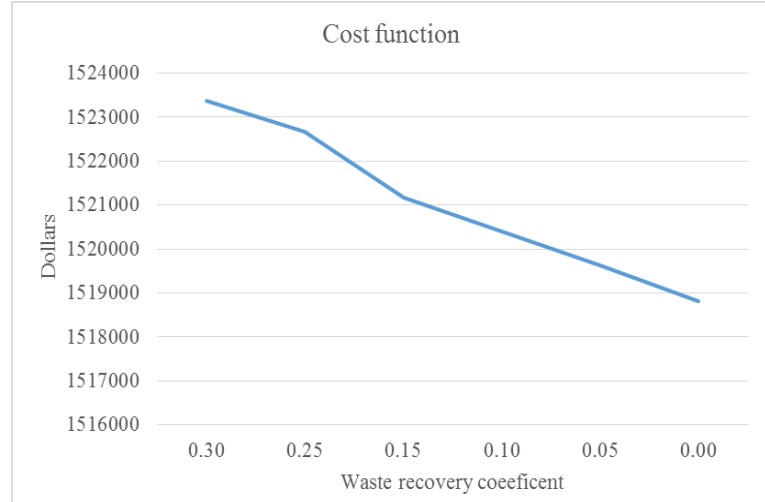

Figure 8. Effects of variation waste recovery coefficient on the cost function.

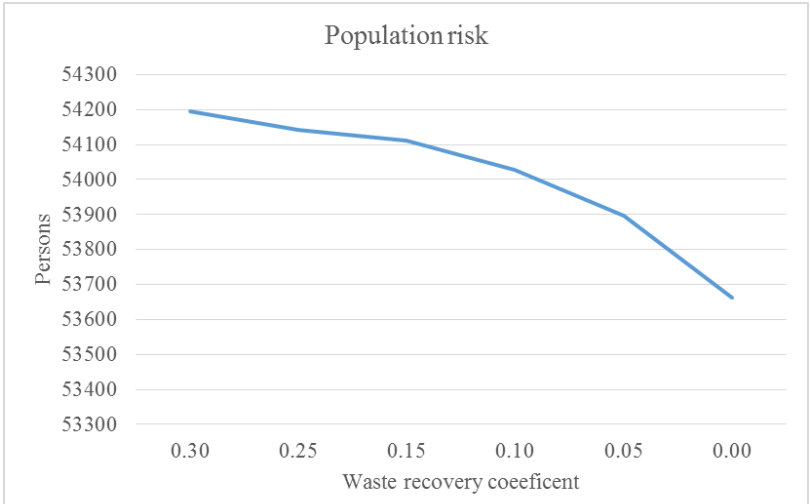

Figure 9. Effects of variation waste recovery coefficient on population risk.

Table 8. Effects of changing waste recovery coefficient.

\begin{tabular}{cccccc}
\hline Problem & $\begin{array}{c}\text { Waste recovery } \\
\text { coefficent }\end{array}$ & Cost function & Time solution & $\begin{array}{c}\text { Cost } \\
\text { variation }\end{array}$ & $\begin{array}{c}\text { Population } \\
\text { risk }\end{array}$ \\
\hline P1 & $30 \%$ & 1523371 & 6.004 & $0.19 \%$ & 54196 \\
P1 & $25 \%$ & 1522667 & 5.436 & $0.15 \%$ & 54142.3 \\
P1 & $15 \%$ & 1521177 & 5.676 & $0.05 \%$ & 54112.7 \\
P1-main model & $10 \%$ & 1520407 & 5.45 & $0.00 \%$ & 54026.3 \\
P1 & $5 \%$ & 1519622 & 5.967 & $-0.05 \%$ & 53897.7 \\
P1 & $0 \%$ & 1518823 & 6.07 & $-0.10 \%$ & 53662.3 \\
\hline
\end{tabular}

\section{4.4. Variation on demand}

235 We test the effects of changing demand. By increasing demand, the cost function increase, too

236 (cf. Table 9). As can be seen, When the demand increases 40\%, the cost function grows $12 \%$ and 237 when demand decreases 50\%, it grows down 16\% (cf. Figure 10 and Figure 11). 


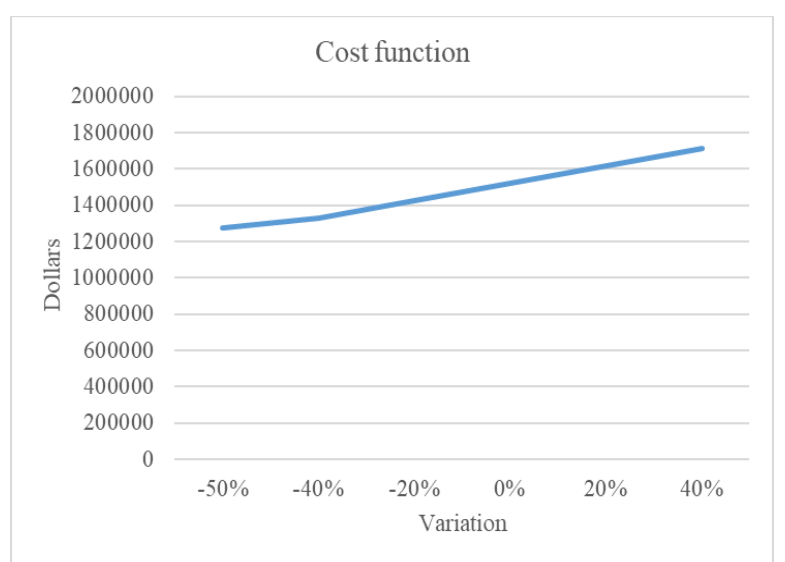

Figure 10. Effects of variation demnad on cost function.

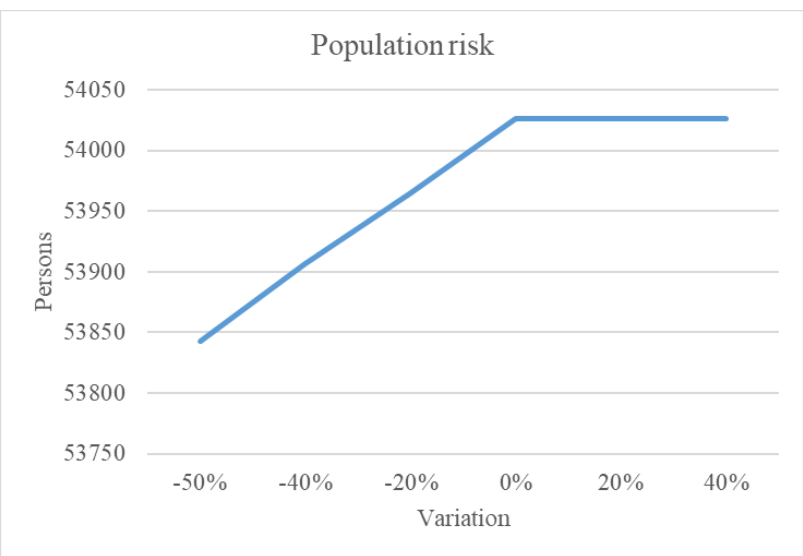

Figure 11. Effects of variation demand on population risk.

Table 9. Effects of changing demand.

\begin{tabular}{cccccc}
\hline Problem & $\begin{array}{c}\text { Changing } \\
\text { demand }\end{array}$ & Cost function & $\begin{array}{c}\text { Time } \\
\text { solution }\end{array}$ & $\begin{array}{c}\text { Cost } \\
\text { variation }\end{array}$ & $\begin{array}{c}\text { Population } \\
\text { risk }\end{array}$ \\
\hline P1 & $-50 \%$ & 1277474.078 & 5.941 & $-15.98 \%$ & 53843.001 \\
P1 & $-40 \%$ & 1326060.712 & 5.888 & $-12.78 \%$ & 53906.334 \\
P1 & $-20 \%$ & 1423233.979 & 6.528 & $-6.39 \%$ & 53965.334 \\
P1-main model & $0 \%$ & 1520407 & 5.45 & $0.00 \%$ & 54026.334 \\
P1 & $+20 \%$ & 1617580.513 & 6.295 & $6.39 \%$ & 54026.334 \\
P1 & $+40 \%$ & 1714753.780 & 5.963 & $12.78 \%$ & 54026.334 \\
\hline
\end{tabular}

\subsection{Variation on scale of the main model}

241 The several large-scale problems is defined in Table 10. When the scale of problems is increased, 242 the time solution and cost function increase in Figure 12 and Figure 13. As can be seen, the 243 proposed model show NP-hard and the behavior of this model is exponential for large scale.

244 Therefore, we need to solve the model by heuristic, metaheuristic and new exact solution in 245 minimum time on large scale.

Table 10. Cost and time solution for several problems.

\begin{tabular}{|c|c|c|c|c|c|c|c|c|}
\hline$\frac{\Xi}{0}$ & $|i| \cdot|j| \cdot|c| \cdot|k| \cdot|t| \cdot|s|$ & 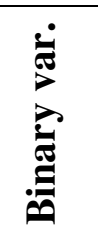 & 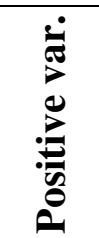 & 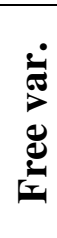 & 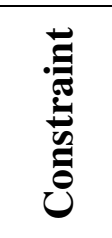 & $\begin{array}{c}\text { Cost } \\
\text { function }\end{array}$ & $\begin{array}{c}\text { Time } \\
\text { solution }\end{array}$ & $\begin{array}{l}\text { Population } \\
\text { risk }\end{array}$ \\
\hline $\mathrm{P} 1$ & 118.4.3.1.3.3 & 4396 & 4393 & 12 & 8818 & 1520407 & 9.422 & 54026.33 \\
\hline $\mathrm{P} 2$ & 10.8.4.2.7.7 & 6280 & 6273 & 20 & 12380 & 609257 & 6.796 & 9201.68 \\
\hline
\end{tabular}




\begin{tabular}{ccccccccc} 
P3 & 118.4 .3 .1 .3 .5 & 7324 & 7321 & 16 & 14694 & 1591272 & 13.49 & 54408.4 \\
P4 & 120.5 .4 .1 .5 .3 & 9380 & 9376 & 12 & 18721 & 1906117 & 21.548 & 91725.33 \\
P5 & 120.5 .4 .2 .7 .3 & 13235 & 13231 & 12 & 36388 & 2160152 & 72.426 & 128016.7 \\
P6 & 120.8 .4 .2 .7 .3 & 21176 & 21169 & 12 & 44578 & 2152882 & 249.904 & 127924 \\
\hline
\end{tabular}

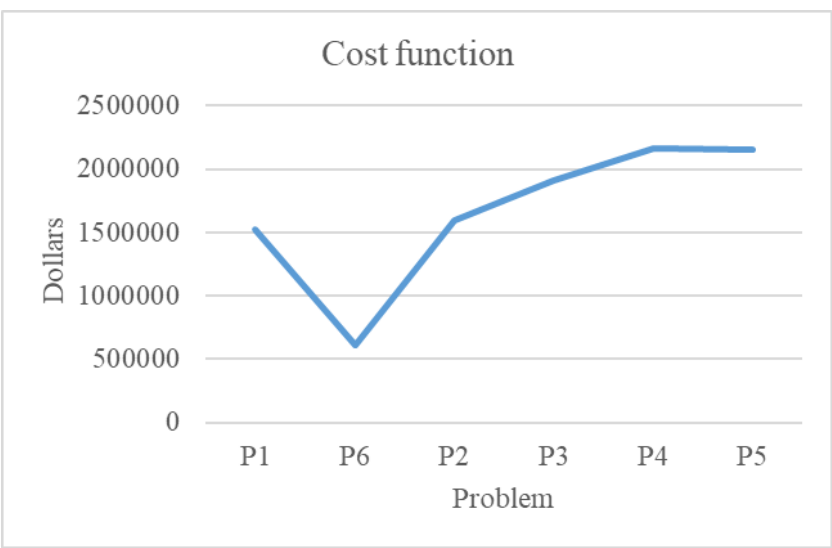

Figure 12. Cost function for several problems.

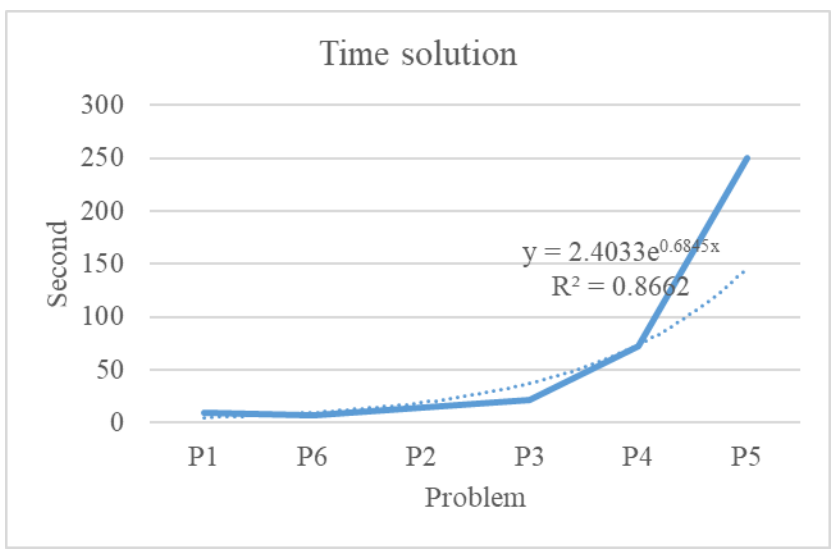

Figure 13. Time solution for several problems.

\section{Managerial insights and practical implications}

249 We surveyed viable waste medical chain network design (VWMCND). We try to pay more 250 attention to five concepts in medical waste network design. We design VWMCND that considers agility, resilience, sustainability, risks and robustness to cope with disruption and requirements of government. As managers of the VWMCND, we should move forward to applying the novel concept in MCND to decrease cost and population risk, increase the resiliency of facility, robustness, risk-averse and agility of network. In this research, we have Health Center (HC), Waste Segregation (WS), Waste Purchase Contractor (WPC) and landfill. We propose to locate WS to decrease waste and recover them and send to the WPC. Recovering medical waste like metal and plastic can help the environment and return to production cycle. In this situation of COVID-19 and because of economic problem, we should use all power to utilize waste and move to circular

259 economy and sustainable development. This issue is compatible Sustainable Development Goal

260 (SDG12-Ensure sustainable consumption and production patterns) and the circular economy 261 pillars.

\section{Conclusions and Outlook}

263 Medical Waste Management (MWM) is an important and necessary problem in the COVID-19 264 situation for treatment staff. The number of infectious patients grows up and amount of MWMs 
increases day by day. We should think about this issue and find a solution for this issue. We suggest to recovery MWM by waste segregation. Therefore, we proposed a novel Viable Medical Waste Chain Network Design (VMWCND) that consider resiliency (flexibility and network complexity) and sustainable (energy and environment) requirement. Finally, we try to tackle decrease risks and increase robustness and agility to demand fluctuation and network. We utilize a novel two-stage robust stochastic programming and solve with a GAMS CPLEX solver.

Therefore, the results are as follows:

1. If the conservative coefficient increases up to 1 , the cost function grows up in If the conservative coefficient increases to 1 , the cost function grows in Table 6, Figure 5 and Figure 6. If the conservative coefficient increases $50 \%$, the cost function will increase by $1.65 \%$, but time solution and population risk do not change significantly.

2. If the conservative coefficient increases up to $50 \%$, the cost function will increase $1.65 \%$, but time solution and population risk do not change significantly.

3. If the confidence level of CVaR grows up, we can see, the cost function will increase (cf. Figure 7 and Table 7). Increasing for confidence level by $2 \%$, the cost function increase $0.03 \%$.

4. If the waste recovery coefficient grows, we can see that the cost function and population risk will decrease (cf. Figure 8, Figure 9 and Table 8). By increasing the waste recovery coefficient, transportation to WPC increases and then the cost function increase. But it helps systems to use waste and recover them.

5. When demand increases $40 \%$, the cost function grows $12 \%$ and when demand decreases $50 \%$, it grows down $16 \%$ (cf. Figure 10 and Figure 11).

6. When the scale of problems is increased, the cost function and time solution grow up in Figure 12 and Figure 13. As can be seen, the behavior of the proposed model is NP-hard and exponential on large scale. Therefore, we need to solve the model by heuristic, metaheuristic and new exact solution in minimum time on large scale.

Finally, solving the main model on a large scale is the research constraint. We propose to apply exact algorithms like benders decomposition, branch and price, branch and cut, column generation, heuristic and meta-heuristic algorithms to solve models in minimum time (Fakhrzad \& Lotfi, 2018; 
Lotfi, Mehrjerdi, \& Mardani, 2017). We can add other resilience and sustainable tools to the model

295 until increasing the resiliency and sustainability of the model like backup facility and redundancy.

296 Further, we suggest adding coherent risk criteria like Entropic Value at Risk (EVaR) (Ahmadi-

297 Javid, 2012) for considering risks. Researchers intend to investigate method uncertainty like robust

298 convex (Lotfi, Mardani, \& Weber, 2021). Using new and novel uncertainty methods like data-

299 driven robust optimization is advantageous for a conservative decision-maker in the recent decade.

300 Eventually, we suggest equipping VMWCND with novel technology like blockchain for the 301 viability of MWCND.

302 7. Ethical Approval

303 Not applicable

304 8. Consent to Participate

305 Not applicable

306 9. Consent to Publish

307 Not applicable

308 10. Authors Contributions

309 Reza Lotfi: conceptualization, supervision, software, methodology; software; formal analysis;

310 data curation; writing original draft; visualization;

311 Bahareh Kargar: methodology; software; formal analysis; data curation; writing original draft;

312 writing review and edit; visualization;

313 Alireza Gharehbaghi: methodology, validation;

314 Gerhard-Wilhelm Weber: validation, writing review and edit;

315 11. Funding

316 There is not funding.

\section{12. Competing Interests}

318 The authors declare no competing interests.

\section{Availability of data and materials}

Not applicable

\section{$321 \quad$ References}

Ahmadi-Javid, A. (2012). Entropic value-at-risk: A new coherent risk measure. Journal of Optimization Theory and Applications, 155(3), 1105-1123.

Aung, T. S., Luan, S., \& Xu, Q. (2019). Application of multi-criteria-decision approach for the analysis of medical waste management systems in Myanmar. Journal of Cleaner Production, 222, 733-745. 
Budak, A., \& Ustundag, A. (2017). Reverse logistics optimisation for waste collection and disposal in health institutions: the case of Turkey. International Journal of Logistics Research and Applications, 20(4), 322341.

Fakhrzad, M.-B., \& Lotfi, R. (2018). Green vendor managed inventory with backorder in two echelon supply chain with epsilon-constraint and NSGA-II approach. Journal of Industrial Engineering Research in Production Systems, 5(11), 193-209.

Goli, A., Zare, H. K., Tavakkoli-Moghaddam, R., \& Sadeghieh, A. (2019). Application of robust optimization for a product portfolio problem using an invasive weed optimization algorithm. Numerical Algebra, Control \& Optimization, 9(2), 187-209.

Gondal, I. A., \& Sahir, M. H. (2013). Model for biomass-based renewable hydrogen supply chain. International Journal of Energy Research, 37(10), 1151-1159.

Homayouni, Z., \& Pishvaee, M. S. (2020). A bi-objective robust optimization model for hazardous hospital waste collection and disposal network design problem. Journal of Material Cycles and Waste Management, 22(6), 1965-1984.

Ivanov, D. (2020). Viable supply chain model: integrating agility, resilience and sustainability perspectives-lessons from and thinking beyond the COVID-19 pandemic. Annals of Operations Research, 1-21.

Ivanov, D., \& Dolgui, A. (2020). Viability of intertwined supply networks: extending the supply chain resilience angles towards survivability. A position paper motivated by COVID-19 outbreak. International Journal of Production Research, 58(10), 2904-2915.

Kara, G., Özmen, A., \& Weber, G.-W. (2019). Stability advances in robust portfolio optimization under parallelepiped uncertainty. Central European Journal of Operations Research, 27(1), 241-261.

Kargar, S., Paydar, M. M., \& Safaei, A. S. (2020). A reverse supply chain for medical waste: A case study in Babol healthcare sector. Waste Management, 113, 197-209.

Kargar, S., Pourmehdi, M., \& Paydar, M. M. (2020). Reverse logistics network design for medical waste management in the epidemic outbreak of the novel coronavirus (COVID-19). Science of the Total Environment, 746, 141183.

Li, H., Hu, Y., Lyu, J., Quan, H., Xu, X., \& Li, C. (2021). Transportation Risk Control of Waste Disposal in the Healthcare System with Two-Echelon Waste Collection Network. Mathematical Problems in Engineering, 2021.

Lotfi, R., Mardani, N., \& Weber, G. W. (2021). Robust bi-level programming for renewable energy location. International Journal of Energy Research.

Lotfi, R., Mehrjerdi, Y. Z., \& Mardani, N. (2017). A multi-objective and multi-product advertising billboard location model with attraction factor mathematical modeling and solutions. International Journal of Applied Logistics (IJAL), 7(1), 64-86.

Lotfi, R., Mehrjerdi, Y. Z., Pishvaee, M. S., Sadeghieh, A., \& Weber, G.-W. (2021). A robust optimization model for sustainable and resilient closed-loop supply chain network design considering conditional value at risk. Numerical Algebra, Control \& Optimization, 11(2), 221.

Mantzaras, G., \& Voudrias, E. A. (2017). An optimization model for collection, haul, transfer, treatment and disposal of infectious medical waste: Application to a Greek region. Waste Management, 69, 518-534.

Narayanamoorthy, S., Annapoorani, V., Kang, D., Baleanu, D., Jeon, J., Kureethara, J. V., \& Ramya, L. (2020). A novel assessment of bio-medical waste disposal methods using integrating weighting approach and hesitant fuzzy MOOSRA. Journal of Cleaner Production, 275, 122587.

Nikzamir, M., Baradaran, V., \& Panahi, Y. (2021). A Supply Chain Network Design for Managing Hospital Solid Waste. Journal of Industrial Management Studies, 19(60), 85-120.

Saeidi-Mobarakeh, Z., Tavakkoli-Moghaddam, R., Navabakhsh, M., \& Amoozad-Khalili, H. (2020). A bi-level and robust optimization-based framework for a hazardous waste management problem: A real-world application. Journal of Cleaner Production, 252, 119830.

Saeidi-Mobarakeh, Z., Tavakkoli-Moghaddam, R., Navabakhsh, M., \& Amoozad-Khalili, H. (2020). A Bi-level Metaheuristic Approach for a Hazardous Waste Management Problem. International Journal of Engineering, 33(7), 1304-1310.

Sepúlveda, J., Banguera, L., Fuertes, G., Carrasco, R., \& Vargas, M. (2017). Reverse and inverse logistic models for solid waste management. South African Journal of Industrial Engineering, 28(4), 120-132.

Shadkam, E. (2021). Cuckoo optimization algorithm in reverse logistics: A network design for COVID-19 waste management. Waste Management \& Research, 0734242X211003947.

Sherali, H. D., \& Adams, W. P. (2013). A reformulation-linearization technique for solving discrete and continuous nonconvex problems (Vol. 31): Springer Science \& Business Media. 
Soleimani, H., \& Govindan, K. (2014). Reverse logistics network design and planning utilizing conditional value at risk. European journal of operational research, 237(2), 487-497.

Suksee, S., \& Sindhuchao, S. (2021). GRASP with ALNS for solving the location routing problem of infectious waste collection in the Northeast of Thailand. International Journal of Industrial Engineering Computations, 12(3), 305-320.

Tirkolaee, E. B., Abbasian, P., \& Weber, G.-W. (2021). Sustainable fuzzy multi-trip location-routing problem for medical waste management during the COVID-19 outbreak. Science of the Total Environment, 756, 143607.

Tirkolaee, E. B., \& Aydın, N. S. (2021). A sustainable medical waste collection and transportation model for pandemics. Waste Management \& Research, 0734242X211000437.

Tsai, W.-T. (2021). Analysis of medical waste management and impact analysis of COVID-19 on its generation in Taiwan. Waste Management \& Research, 0734242X21996803.

Wang, Z., Huang, L., \& He, C. X. (2019). A multi-objective and multi-period optimization model for urban healthcare waste's reverse logistics network design. Journal of Combinatorial Optimization, 1-28.

Yu, H., Sun, X., Solvang, W. D., Laporte, G., \& Lee, C. K. M. (2020). A stochastic network design problem for hazardous waste management. Journal of Cleaner Production, 277, 123566.

Yu, H., Sun, X., Solvang, W. D., \& Zhao, X. (2020). Reverse logistics network design for effective management of medical waste in epidemic outbreaks: Insights from the coronavirus disease 2019 (COVID-19) outbreak in Wuhan (China). International journal of environmental research and public health, 17(5), 1770. 